\title{
Stress-strain state analysis and optimization of rod system under periodic pulse load
}

\author{
Grigory Grebenyuk ${ }^{1, *}$, Maxim Veshkin ${ }^{1}$, Vladislav Maksak $^{2}$, and Olga Nosireva ${ }^{1}$ \\ ${ }^{1}$ Novosibirsk State University of Architecture and Civil Engineering (Sibstrin), 630008 Novosibirsk, \\ Russia \\ ${ }^{2}$ Tomsk State University of Architecture and Building, 634003 Tomsk, Russia
}

\begin{abstract}
The paper considers the problem of analysis and optimization of rod systems subjected to combined static and periodic pulse load. As a result of the study the analysis method was developed based on traditional approach to solving homogeneous matrix equations of state and a special algorithm for developing a particular solution. The influence of pulse parameters variations on stress-strain state of a rod system was analyzed. Algorithms for rod systems optimization were developed basing on strength recalculation and statement and solution of optimization problem as a problem of nonlinear mathematical programming. Recommendations are developed for efficient organization of process for optimization of rod systems under static and periodic pulse load.
\end{abstract}

\section{Introduction}

To date, multiple investigations have been performed in the field of design and optimization of rod systems under static and dynamic load [1, 2, 8, 10-17]. In the majority of them, harmonic loads serve as dynamic ones. In a number of studies $[2,3,5,6]$ the emphasis is put on determination of optimal systems properties in optimization problems with constraints of strength, stiffness and lowest frequency of natural vibrations.

Previous research [7, 9-13, 15] were focused on decrease of labor intensity for optimization algorithms, first of all, due to more efficient organization (effective analysis and optimization methods, effective methods of structural state parameters approximation in iteration optimization processes, division of optimization process into levels and stages, etc.). In particular, the work [11] suggests combining the numerical procedure of dynamic analysis and the algorithm of finite difference approximation of structural state parameters to improve efficiency of optimization process for systems dynamic loading.

In recent years, a tendency to build processes of structural optimization without using approximation of structural state parameters appeared $[16,17]$. However, development of efficient methods for analysis and optimization of structures under static and periodic pulse load is a relevant task. The purpose of this research is development of convenient and effective methods for analysis and optimization of rod systems under combined static and periodic pulse load.

\footnotetext{
* Corresponding author: greb@sibstrin.ru
} 


\section{Analysis procedure and optimization}

\subsection{Brief description of dynamic analysis procedure}

Equation of equilibrium of a discrete dynamic system (without the account of damping and with regard to the method of finite elements displacement) is written as follows:

$$
r_{m} \cdot \ddot{Z}(t)+r_{e} \cdot Z(t)+R_{F}(t)=0
$$

where $\boldsymbol{r}_{\boldsymbol{m}}, \boldsymbol{r}_{\boldsymbol{e}}$ - matrices of mass and stiffness, $\boldsymbol{R}_{\boldsymbol{F}}(\boldsymbol{t})$ - vector of dynamic load.

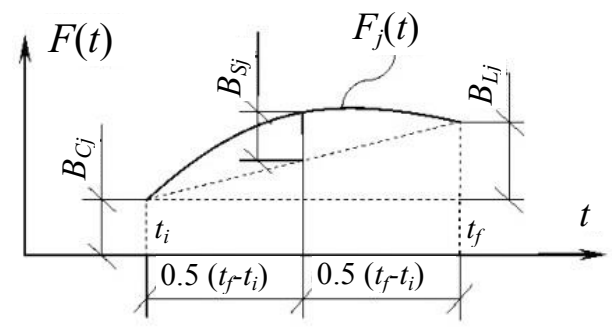

Fig.1. Approximation of dynamic action in a time interval.

Dependence of load value on time of interpulse interval is approximated by invariable, linear and sinusoidal components (Fig. 1).

In case when the interpulse interval exceeds the pulse duration, there are time intervals in which the system executes forced and free vibrations (Fig. 2).

In the first case (interval 1) the solution is as follows [1]:

$$
Z(t)=\bar{Z}(t)+\tilde{Z}(t)
$$

where $-\overline{\boldsymbol{Z}}(\boldsymbol{t})-$ general solution of the homogeneous equation.

$$
r_{m} \cdot \ddot{Z}(t)+r_{e} \cdot Z(t)=0
$$

$\tilde{\boldsymbol{Z}}(\boldsymbol{t})$ - particular solution (1), sought in the form of

$$
\tilde{Z}(\boldsymbol{t})=\boldsymbol{Q} \cdot \boldsymbol{L}(\boldsymbol{t})
$$

$\boldsymbol{L}(\boldsymbol{t})$ - vector of approximating functions, $\boldsymbol{Q}$ - numerical matrix, constants of integration are found from the initial conditions.

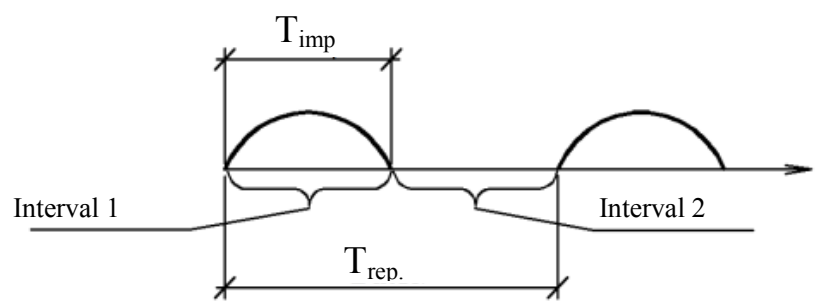

Fig. 2. Periodic pulse action in time. 
In the second case (interval 2), the general solution is the solution of the homogeneous equation (3), whereas constants of integration are found from the conditions of the solutions interface in the intervals 1 and 2 . Then, the recalculation procedure repeats, in which the initial conditions for defining constants of integration on interval 1 for the next period are the calculation results on interval 2 for the previous period.

A single-span pin-supported beam with its own mass $(\tilde{\boldsymbol{m}}=0.13659 \mathrm{t} / \mathrm{m})$ evenly distributed along the longitudinal axis and with three concentrated masses $(\boldsymbol{m}=0.5 \mathrm{t})$ fixed on the longitudinal axis was used as an experimental structure subjected to periodic pulse load. Length of the beam is $\boldsymbol{l}=4 \mathrm{~m}$, its stiffness is $\boldsymbol{E I}=838400 \mathrm{kN} \cdot \mathrm{m}^{2}$. Pulse loading was applied to the beam in the form of concentrated force. The size of pulse stayed the same while its shape and duration were varied. Two variants of pulse load application are considered: force at quarter-span (Fig. 3a); and force at mid-span (Fig. 3b).

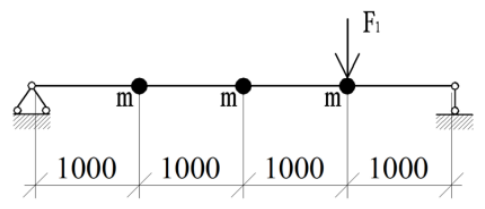

a)

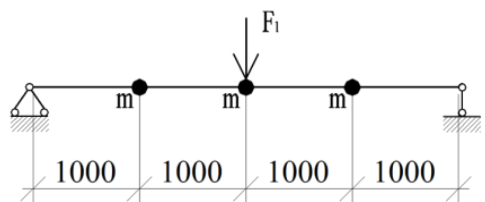

b)

Fig. 3. Design schemes for beam: a) pulse action at quarter-span; b) pulse action at mid-span.

\subsection{Analysis of effect of pulse frequency}

Influence of pulse repetition frequency $\boldsymbol{n}_{\text {rep }}$ (with repetition period $\boldsymbol{T}_{\text {rep }}$ ) on the maximum value of bending moment in the beam cross-section was analyzed at the initial stage of research. Sinusoidal shape of pulse was accepted for analysis (Fig. 2). First 40 pulses were studied at determined intervals. The analysis was performed with the help of DINAM software based on the method of finite elements displacement and developed at the Structural Mechanics Department of Novosibirsk State University of Architecture and Civil Engineering (Sibstrin). The software allows analyzing rod systems for arbitrary dynamic loads with calculation of natural vibration frequencies.

In the process of the beam vibration under pulse action the maximum values of bending moments were selected in the cross-sections taken every $0.2 \mathrm{~m}$ along the beam.

Analysis was performed at the constant duration and amplitude of force action $\left(\boldsymbol{T}_{\text {imp }}=0.008 \mathrm{~s}, \boldsymbol{F}_{\text {max }}=10 \mathrm{kN}\right)$. Frequency of pulse load varied from $3 \mathrm{~Hz}$ to $125 \mathrm{~Hz}$, which

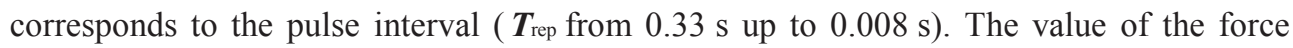
pulse was $0.05055 \mathrm{kN} \cdot \mathrm{s}$.

The considered frequency range of periodic pulse load contained 2 natural frequencies of the beam: $\mathrm{f}_{1}=15.12 \mathrm{~Hz}, \mathrm{f}_{2}=60.13 \mathrm{~Hz}$.

Figure 4 demonstrates a fragment of the dependence graph for bending moment amplitude on pulse frequency. The green line corresponds to the pulse applied to quarterspan, the pink one - to the pulse applied to mid-span. 


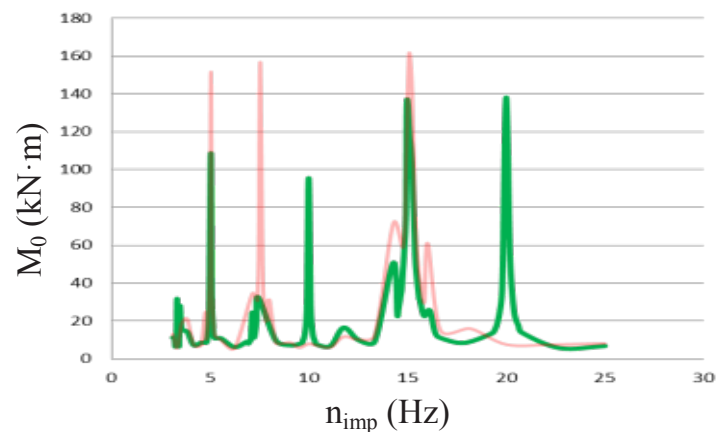

Fig. 4. Dependence of bending moments amplitude on pulse frequency.

As it was assumed, the resonance effect occurred near the natural frequency regions, but the peak values were slightly displaced with regard to natural frequencies. Beside, resonance phenomena were observed at the pulse frequencies divisible by frequencies of natural vibrations. These peaks of amplitudes are obviously caused by harmonic resonance.

\subsection{Analysis of the effect of pulse shape and duration}

The effect of pulse shape was analyzed on the example of the beam under load at quarterspan. Two pulse shapes were considered (Fig. 5.):

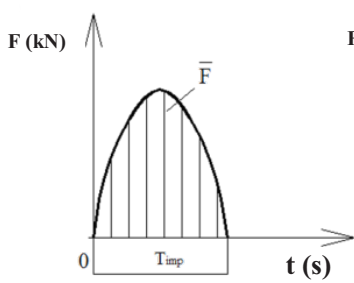

a)

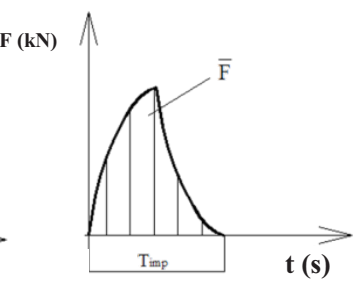

b)

Fig. 5. a) sinusoidal pulse; b) wave pulse.

The pulse size is constant. Figure 6 demonstrates the graph with the analysis results under action of wave pulse (gray line) and sinusoidal pulse (red line). The graph clearly shows that wave pulse is the most dangerous. The maximum value of force under wave pulse action appears to be $30 \%$ higher than that under sinusoidal pulse action.

Then, the effect of pulse duration was investigated on the example of a beam under load at quarter-span. Figure 7 presents dependences of the maximum bending moment amplitude for various relations $\boldsymbol{T}_{\text {imp }} / \boldsymbol{T}_{\text {rep }}$, with

$\boldsymbol{T}_{\text {rep }}=0.01663 \mathrm{~s}$ corresponding to the second own frequency $\boldsymbol{n}_{2}=60.13$;

$\boldsymbol{T}_{\text {rep }}=0.044 \mathrm{~s}-$ non-resonance case.

When increasing the pulse duration $\boldsymbol{T}_{i m p}$ the maximum values of bending moment amplitude decrease. In some near-resonance points the graph possesses considerable nonlinearity, which is related to resonance effects. 


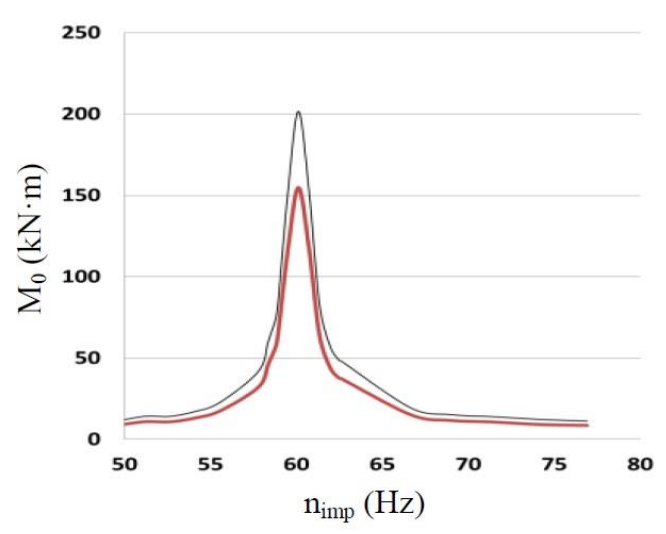

Fig. 6. Dependence of amplitude of bending moments vibrations on pulse frequency.
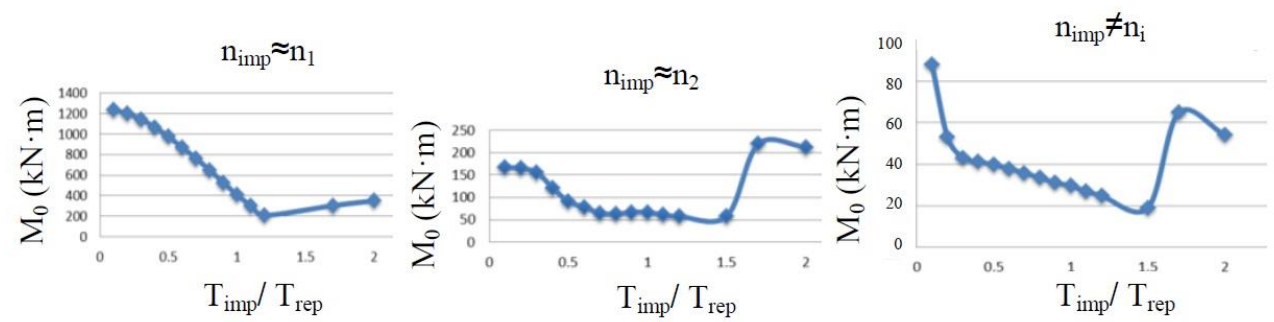

Fig.7. Dependence of $\boldsymbol{M}_{0}$ on pulse duration for various values of $\boldsymbol{n}_{\boldsymbol{i m p} \text {. }}$

As the result of the investigation wave pulse was found more dangerous than sinusoidal one. Drop of maximum bending moment amplitude is observed in the weakest cross-section when duration of pulse with set frequency was increased; however, in case of two pulses overlap the amplitude shows a sharp rise. Variation of pulse frequency also has a remarkable effect on the values of bending moments amplitudes.

These research outcomes were further used in statement of the frame structure optimization problem with the account of the most negative cases of periodic pulse loading.

\subsection{Solution of optimization problem for a steel frame subjected to static and periodic pulse load}

A five-floor double-span steel frame made of welded I-shaped elements was taken as an example for optimization problem statement for a structure subjected to combined static and periodic pulse load $\boldsymbol{q}(\boldsymbol{t})$ (Fig.8). The floor height is $3 \mathrm{~m}$, section span is $6 \mathrm{~m}$. Wave pulse is considered. 


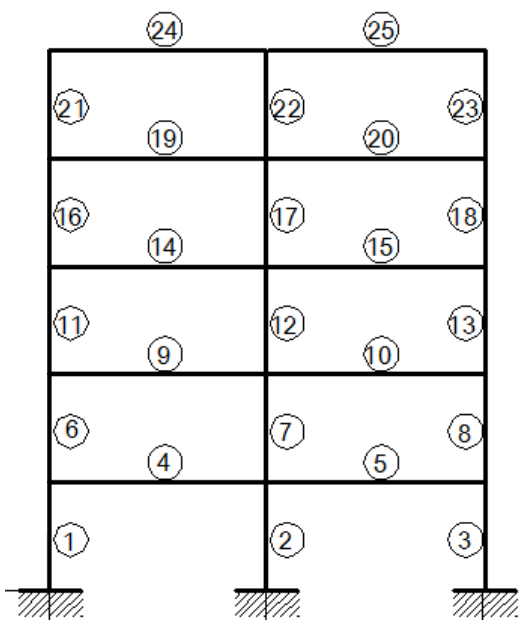

a)

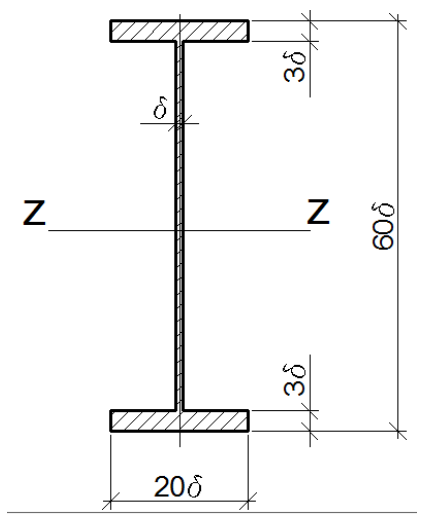

b)

Fig. 8. a) frame analysis scheme; b) shape of elements' cross-sections.

The frame consists of 25 elements ( 15 columns and 10 cross-beams). Frame loading scheme is showed in Figure 9. Characteristics of cross-sections of columns and cross-beams depend on the $\delta$ parameter: cross-section area $\boldsymbol{A}=174 \cdot \delta^{2}$; cross-section's moment of inertia $\boldsymbol{I}_{z}=110682 \cdot \delta^{4} ;$ cross-section's moment of resistance $\boldsymbol{W}_{z}=3689.4 \cdot \delta^{3}$. The following parameters of the frame elements material were accepted: material - steel; material density $\rho=7850\left(\mathrm{~kg} / \mathrm{m}^{3}\right)$; elastic modulus $\boldsymbol{E}=2.1 \cdot 10^{5}(\mathrm{MPa})$; design resistance $\boldsymbol{R}=200(\mathrm{MPa})$.

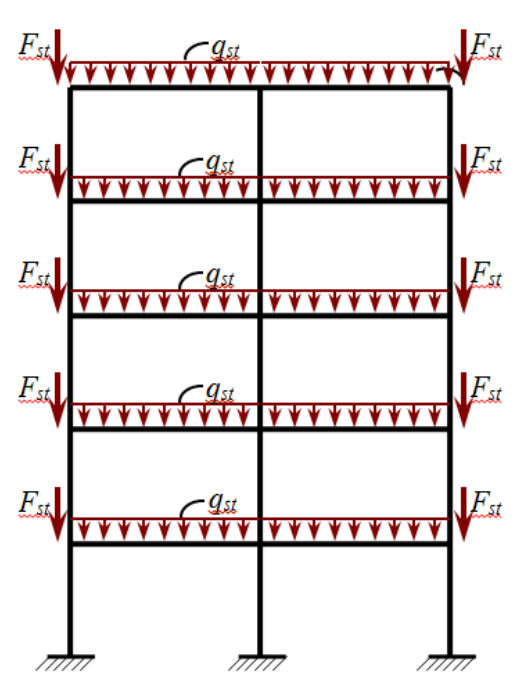

a)

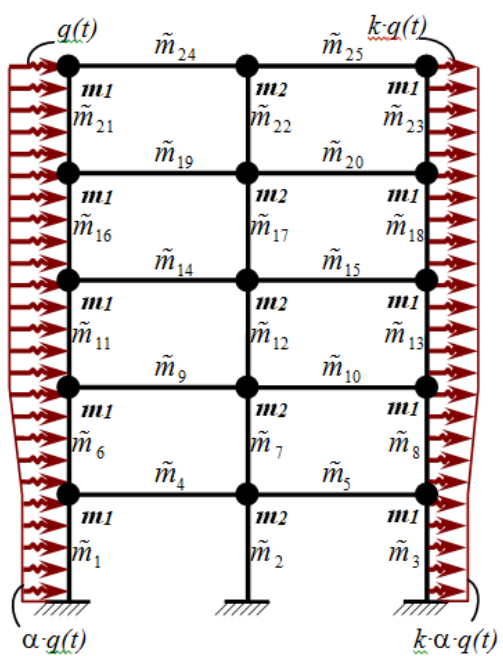

b)

Fig. 9. Frame loading scheme: a) static; b) dynamic. 
2.4.1 Optimum design development based on iteration algorithms of strength recalculation

Admitted design with identical cross-sections of frame elements

The function of frame material volume was accepted as an objective function. With identical cross-sections of frame elements the function has the following form:

$$
\boldsymbol{f}(\boldsymbol{X})=\left(15 \cdot \boldsymbol{l}_{c o l}+10 \cdot \boldsymbol{l}_{c b}\right) \cdot 174 \cdot \boldsymbol{X}_{1}^{2}
$$

where $\boldsymbol{l}_{c o l}$ - length of columns; $\boldsymbol{l}_{c b}$ - length of cross-beams.

The value of $\boldsymbol{X}_{1}=\delta$ was recalculated based on fulfillment of the following condition:

$$
\max _{i=1, \ldots, 25} \frac{\frac{\left|\boldsymbol{M}_{\boldsymbol{i}}\right|_{\max }}{3689.4 \cdot \boldsymbol{X}_{1}^{3}}+\frac{\left|\boldsymbol{N}_{\boldsymbol{i}}\right|_{\text {cor. }}}{174 \cdot \boldsymbol{X}_{1}^{2}}}{2 \cdot 10^{5}}-1=0
$$

where $\left|\boldsymbol{M}_{\boldsymbol{i}}\right|_{\max },\left|\boldsymbol{N}_{\boldsymbol{i}}\right|_{\text {cor. }}$ - maximum modulo value of bending moment and the modulo value of longitudinal force in $\boldsymbol{i}$ frame element.

The problem was solved in the Digital Visual Fortran environment. As the result of the performed analysis the admitted solution $\boldsymbol{X}_{1}^{*}=0.00818 \mathrm{~m}$ and the value of objective function $\boldsymbol{f}\left(\boldsymbol{X}^{*}\right)=1.22 \mathrm{~m}^{3}$ were obtained. Active strength constraint is in the second element. Constraints on frame joints displacements were disregarded.

\section{Optimum design for two groups of frame elements (columns, cross-beams)}

The function of frame material volume was accepted as an objective function.

$$
\boldsymbol{f}(\boldsymbol{X})=15 \cdot \boldsymbol{l}_{\mathrm{col}} \cdot 174 \cdot \boldsymbol{X}_{1}^{2}+10 \cdot \boldsymbol{l}_{c b} \cdot 174 \cdot \boldsymbol{X}_{2}^{2},
$$

where $\boldsymbol{X}_{1}=\delta_{1}, \boldsymbol{X}_{2}=\delta_{2}$ - size parameters of columns and cross-beams. Strength constraints similar to (6) were obtained for each group of elements:

- for columns

$$
\max _{\substack{i=N E G 1(j) \\ j=1, \ldots, 15}} \frac{\frac{\left|\boldsymbol{M}_{\boldsymbol{i}}\right|_{\max }}{3689.4 \cdot \boldsymbol{X}_{1}^{3}}+\frac{\left|\boldsymbol{N}_{\boldsymbol{i}}\right|_{\text {cor. }}}{174 \cdot \boldsymbol{X}_{1}^{2}}}{2 \cdot 10^{5}}-1=0
$$

- for cross-beams

$$
\max _{\substack{i=N E G 2(j) \\ j=1, \ldots, 10}} \frac{\frac{\left|\boldsymbol{M}_{\boldsymbol{i}}\right|_{\max }}{3689.4 \cdot \boldsymbol{X}_{1}^{3}}+\frac{\left|\boldsymbol{N}_{\boldsymbol{i}}\right|_{\text {cor. }}}{174 \cdot \boldsymbol{X}_{1}^{2}}}{2 \cdot 10^{5}}-1=0
$$

where $\boldsymbol{N E G 1}(\boldsymbol{j}), \boldsymbol{N E G} 2(\boldsymbol{j})$ - number of groups of elements in the common list of frame elements.

The problem was solved in the Digital Visual Fortran software environment with the use of the developed IMPULSR software module. The following results were obtained while analyzing:

- the optimal values of the varied parameters $\boldsymbol{X}_{1}^{*}=0.00819 \mathrm{~m}, \boldsymbol{X}_{2}^{*}=0.00674 \mathrm{~m}$; 
- the value of the objective function in the optimum design $f\left(X^{*}\right)=1.00 \mathrm{~m}^{3}$.

Optimum design for ten groups of frame elements (columns and cross-beams on each floor) While performing analysis the elements were divided into 10 groups with respect to the floors ( 5 groups of columns, $i=3,5,7,9 ; 5$ groups of cross-beams, $i=2,4,6,8,10 ;-$ number of groups).

As before, the function of the frame material volume was accepted as objective function $f(X)$.

$$
\boldsymbol{f}(\boldsymbol{X})=\boldsymbol{V}(\boldsymbol{X})=\sum_{i=1,3,5,7,9} 3 \cdot \boldsymbol{l}_{c o l} \cdot 174 \cdot \boldsymbol{X}_{i}^{2}+\sum_{i=2,4,6,8,10} 2 \cdot \boldsymbol{l}_{c b} \cdot 174 \cdot \boldsymbol{X}_{i}^{2}
$$

where $\boldsymbol{X}_{i}=\delta_{i}-$ varied parameter of i group of frame elements.

Strength constraints similar to (8) and (9) were obtained for each group of elements: - for columns

$$
\max _{\substack{j=N G E i(k), k=1,2,3}} \frac{\frac{\left|\boldsymbol{M}_{i j}\right|_{\max }}{3689.4 \cdot \boldsymbol{X}_{i}^{3}}+\frac{\left|\boldsymbol{N}_{\boldsymbol{i} j}\right|_{\text {cor. }}}{174 \cdot \boldsymbol{X}_{i}^{2}}}{2 \cdot 10^{5}}-1 \leq 0, \quad i=1,3,5,7,9
$$

- for cross-beams

$$
\max _{\substack{j=N G E i(k), k=1,2}} \frac{\frac{\left|\boldsymbol{M}_{i j}\right|_{\max }}{3689.4 \cdot \boldsymbol{X}_{i}^{3}}+\frac{\left|\boldsymbol{N}_{i j}\right|_{\text {cor. }}}{174 \cdot \boldsymbol{X}_{i}^{2}}}{2 \cdot 10^{5}}-1 \leq 0, i=2,4,6,8,10
$$

where $\boldsymbol{i}$ - elements group number; $\boldsymbol{j}=\boldsymbol{N} \boldsymbol{G E \boldsymbol { i }}(\boldsymbol{k})$ - the number of group $\boldsymbol{i}$ in the common list of frame elements.

The values of varied parameters in the optimum design are given in Tables 1 and 2.

Table 1. Values of varied parameters in columns ( $\mathrm{mm})$.

\begin{tabular}{|c|c|c|c|c|}
\hline $\boldsymbol{X}_{1}^{*}$ & $\boldsymbol{X}_{3}^{*}$ & $\boldsymbol{X}_{5}^{*}$ & $\boldsymbol{X}_{7}^{*}$ & $\boldsymbol{X}_{9}^{*}$ \\
\hline 8.03 & 7.07 & 6.34 & 5.94 & 6.18 \\
\hline
\end{tabular}

Table 2. Values of varied parameters in cross-beams (mm).

\begin{tabular}{|c|c|c|c|c|}
\hline $\boldsymbol{X}_{2}^{*}$ & $\boldsymbol{X}_{4}^{*}$ & $\boldsymbol{X}_{6}^{*}$ & $\boldsymbol{X}_{8}^{*}$ & $\boldsymbol{X}_{10}^{*}$ \\
\hline 6.61 & 6.58 & 6.55 & 6.59 & 6.49 \\
\hline
\end{tabular}

The value of the objective function $\boldsymbol{f}\left(\boldsymbol{X}^{*}\right)=0.808 \mathrm{~m}^{3}$.

The following conclusions can be made after the data analysis:

1. Parameters of column cross-sections decrease from first to fifth floor. Cross-sections of columns of fourth and fifth floors are slightly off the dependence, the cross-section of fifth floor column being slightly bigger than that of fourth floor column;

2. The parameters of cross-beam sections are quite stable and fluctuate between $6.61 \mathrm{~mm}$ and $6.44 \mathrm{~mm}$. Due to this fact, cross-beams can be integrated in one group for all floors and unified. 
Analysis performed with the use of the developed algorithm for strength recalculation with 25 independent varied parameters of frame elements allowed improving the optimum design with the minimum volume $\boldsymbol{f}\left(\boldsymbol{X}^{*}\right)=0.765 \mathrm{~m}^{3}$. However, such design leads to the increase of labor intensity for frame production and installation because of considerably higher number of unified groups. In all studied cases maximum horizontal displacement of top frame joints was higher than the set tolerance $[\boldsymbol{V}]=0.015 \mathrm{~m}=15 \mathrm{~mm}$. It also shall be noted that the use of strength recalculation algorithm does not account constraints on stiffness, stability and vibrations frequency. In this case, the optimization problem shall have the form of a problem for nonlinear mathematical programming $[10,12,14,17]$.

\subsubsection{Solution of optimization problem in the form of mathematical programming problem with constraints on strength and stiffness.}

Statement and solution of such problems is considered on the example of frame optimization with elements divided into two and ten groups.

Optimum design for two groups of frame elements (columns, cross-beams)

The frame optimization process is organized in iterations. The objective function and strength constraints are represented in relations (7), (8), (9); forces in elements are accepted as constant and are found by analyzing the frame in the initial search point. Stiffness constraint has the following form:

$$
\frac{V_{\max }(X, t)}{[V]}-1 \leq 0
$$

where $\boldsymbol{V}_{\max }-$ horizontal displacement of frame joints; $[\boldsymbol{V}]$ - allowable displacement admitted to be equal to $0.001 \cdot \boldsymbol{H}, \boldsymbol{H}$ - frame height. Linear local approximations $\boldsymbol{V}_{\max }^{\boldsymbol{k}}(\boldsymbol{X}, \boldsymbol{t})$ were built using Taylor series with retention of fixed and linear terms. Elements of gradient of the function $\boldsymbol{V}_{\max }(\boldsymbol{X}, \boldsymbol{t})$ were defined in finite differences:

$$
\frac{\partial \boldsymbol{V}_{\max }\left(\boldsymbol{X}_{0}^{\boldsymbol{k}}, \boldsymbol{t}_{0 \mathrm{P}}^{k}\right)}{\partial \boldsymbol{X}_{\boldsymbol{i}}} \approx \frac{\boldsymbol{V}_{\max }\left(\boldsymbol{X}_{0}^{\boldsymbol{k}}+\Delta \boldsymbol{X}_{\boldsymbol{i}}, \boldsymbol{t}_{\mathrm{0P}}^{\boldsymbol{k}}\right)-\boldsymbol{V}_{\max }\left(\boldsymbol{X}_{0}^{\boldsymbol{k}}-\Delta \boldsymbol{X}_{\boldsymbol{i}}, \boldsymbol{t}_{0 \mathrm{P}}^{\boldsymbol{k}}\right)}{2 \Delta \boldsymbol{X}_{\boldsymbol{i}}}, \quad i=1,2,
$$

where $\boldsymbol{X}_{0}^{\boldsymbol{k}}-$ initial point of search and the point of danger at iteration $\boldsymbol{k} ; \Delta \boldsymbol{X}_{\boldsymbol{i}}-$ step size at the variable $\boldsymbol{X}_{\boldsymbol{i}}$.

The following frame optimization results were obtained: $\boldsymbol{X}_{1}^{*}=0.0087 \mathrm{~m}, \boldsymbol{X}_{2}^{*}=0.00717 \mathrm{~m}$; the value of the objective function in the optimum design is $\boldsymbol{f}\left(\boldsymbol{X}^{*}\right)=1.14 \mathrm{~m}^{3}$. The $14 \%$ increase in volume if compared to the optimum design which was found using the algorithm of strength recalculation can be explained by active stiffness constraint.

The following results were obtained when using the suggested algorithm and dividing the frame elements into 10 groups:

Table 3. Values of varied parameters in columns (mm).

\begin{tabular}{|l|l|l|l|l|}
\hline $\boldsymbol{X}_{1}^{*}$ & $\boldsymbol{X}_{3}^{*}$ & $\boldsymbol{X}_{5}^{*}$ & $\boldsymbol{X}_{7}^{*}$ & $\boldsymbol{X}_{9}^{*}$ \\
\hline 9.1 & 8.8 & 8.2 & 8.1 & 7.9 \\
\hline
\end{tabular}


Table 4. Values of varied parameters in cross-beams ( $\mathrm{mm})$.

\begin{tabular}{|l|l|l|l|l|}
\hline $\boldsymbol{X}_{2}^{*}$ & $\boldsymbol{X}_{4}^{*}$ & $\boldsymbol{X}_{6}^{*}$ & $\boldsymbol{X}_{8}^{*}$ & $\boldsymbol{X}_{10}^{*}$ \\
\hline 7.2 & 7.1 & 6.9 & 6.8 & 6.7 \\
\hline
\end{tabular}

The value of the objective function in the optimum design equals $\boldsymbol{f}\left(\boldsymbol{X}^{*}\right)=0.92 \mathrm{~m}^{3}$. The frame material volume increased by $13.8 \%$ compared to the optimum design previously developed using the strength recalculation algorithm without the account of stiffness constraints, which practically coincides with the case when the frame elements were divided into 2 groups.

\section{Conclusion}

The results of the conducted research demonstrate that the developed analysis method for rod systems subjected to combined static and periodic pulse load requires less labor intensity while providing highly accurate results. Due to analyzing the effects of various characteristics of periodic pulse loading the most negative factors were determined; they shall be accounted in statement and solution of optimization problems for structures subjected to combined static and periodic pulse loads.

An alternative to the iteration algorithm for development of optimization solutions based on approximation of state parameters is the optimization algorithm without approximations within the selected method of conditional extremum problem solution. Every time when it is required to find the values of state parameters included in expression of constraints one refers to the programs for solving system state equations corresponding to the point of search. This makes the optimization process much more labor intensive and emphasizes the need of simpler methods for recalculation of systems subjected to dynamic loads.

\section{References}

1. R. Klaf, D. Zh. Penzien, Dynamics of Structures, (Stroyizdat, Moscow, 1979) (in Russian)

2. L.S. Lyakhovich, A.V. Izhendeev, News of higher educational institutions. Construction, 7, 11-14 (1998) (in Russian)

3. L.S. Lyakhovich, Osobye svojstva optimal'nyh sistem i osnovnye napravlenija ih realizacii $v$ metodah rascheta sooruzhenij [Special properties of optimal systems and the main directions of their implementation in the calculating methods of structures] (TSUAB Publ.House, Tomsk, 2009) (in Russian)

4. L.S. Lyakhovich, Vestnik of TSUAB, 4(45), 70-80 (2014) (in Russian)

5. R.P. Moiseenko, Vestnik of TSUAB, 2(43), $72-79$ (2014) (in Russian)

6. R.P. Moiseenko, Stroitel'stvo [Civil Engineering], 6, 123-126 (2008) (in Russian)

7. L.A. Schmit, Structural Optimization. Some Key Ideas and Insights, in: New Directions in Optimum Structural Design, 1-45 (Wiley, 1984)

8. I.B. Lazarev, Osnovy optimal'nogo proektirovanija konstrukcij. Zadachi i metody [Fundamentals of optimal structural design. Tasks and methods] (Siberian Transport University, Novosibirsk, 1995) (in Russian)

9. I.M. Rabinovich, Raschet konstrukcij minimal'nogo vesa pod dejstviem kratkovremennyh dinamicheskih nagruzok [Calculation of the structures with minimum weight under the effect of short-term dynamic loads] (VIA, Moscow, 1965) (in Russian) 
10. T.T. Feng, J.S. Arora, E.J. Haug, Int. J. Numerical Methods in Eng., 1, 39-52 (1977)

11. Kh. Jakimova, Proektirovanie optimal'nyh dinamicheski nagruzhennyh konstrukcij. Novye napravlenija $v$ stroitel'nom proektirovanii [Designing of optimal dynamically loaded structures. New directions in construction design], 245-262 (Strojizdat, Moscow, 1989) (in Russian)

12. G.I. Grebenyuk, V.I. Roev, M.A. Dimitrov, Proceedings of the $5^{\text {th }}$ All Russian Seminar "Problems of optimal structural design", 119-131 (Sibstrin, Novosibirsk, 2005) (in Russian)

13. E. Hogg, K. Choi, V. Komkov, Structural Sensitivity Analysis (Mir, Moscow, 1998) (in Russian)

14. G.I. Grebenyuk, V.V., Bezdelev, Voprosy dinamiki i prochnosti v mashinostroenii [dynamics and strength issues in engineering], 34-40 (OmSTU, Omsk, 1983) (in Russian)

15. W.C. Mills-Curran, L.A. Schmit, AIAA Journal, 23(1), 132-138 (1985)

16. G.I. Grebenyuk, M.S. Veshkin, Izvestiya of Altai State University, 1, 36-39, (AltGU, Barnaul, 2012) (in Russian)

17. T.L. Dmitrieva, Le Chan Min Dat, Nguen Van Ty, Realizacija algoritmov chislennoj optimizacii v sovremennyh programmny kompleksah [Implementation of numerical optimization algorithms in modern software] (IRNTU, Irkutsk, 2015) (in Russian) 